\title{
Relação da Regulamentação Brasileira do Leite com a Qualidade deste Produto entre 2000 e 2020: Revisão Bibliográfica, Situação Atual e Tendências
}

\section{Relation of Milk Brazilian Regulation and the Quality of this Product between 2000 and 2020: Bibliographic Review, Current situation and Trends}

\author{
Rogério Luiz Vanot ${ }^{\mathrm{a}}$; Veronica Cristina Heringera ; Rafael Fagnani*a
}

aUnopar, Programa de Pós-Graduação Stricto Sensu em Saúde e Produção Animal. PR, Brasil.

*E-mail: rafaelfagnani@hotmail.com

\begin{abstract}
Resumo
O objetivo deste trabalho foi realizar uma revisão bibliográfica sobre a qualidade do leite cru produzido entre os anos de 2000 e 2020 e relacionar esses resultados às exigências das Instruções Normativas, que regulamentam os critérios de identidade e qualidade desse tipo de leite, além de discutir as possíveis tendências relativas à atividade leiteira. Os resultados apontam que ainda não há uniformidade na qualidade do leite cru após quase 20 anos de regulamentações. A melhoria de qualidade também não é nítida em relação aos dados provenientes das publicações científicas, as quais estão concentradas em Minas Gerais, Goiás e Paraná e sem ocorrência nos Estados da região Norte. Verifica-se uma certa dificuldade dos produtores no cumprimento das exigências, principalmente, quando essas se tornaram mais rigorosas, com a publicação de novos limites. Sem incentivos e treinamentos, essa atividade, provavelmente, será exercida cada vez mais por grandes produtores, com um número alto de animais e elevada produtividade.
\end{abstract}

Palavras-chave: Legislação. Leite. Instruções Normativas.

\begin{abstract}
The objective of this study was conducting a literature review on the raw milk quality produced between 2000 and 2020 and relate these results to the Normative Instructions requirements that regulate the identity criteria and quality of this type of milk, in addition to discussing the possible trends regarding milk activity. The results indicate that there is still no uniformity in the raw milk quality after almost 20 years of regulations. The quality improvement related to the data from scientific publications is also not clear, being concentrated in Minas Gerais, Goiás and Paraná and without occurrence in the states of the northern region. There is a certain difficulty for the producers meeting the requirements, especially when they have become more stringent, with the publication of new limits. Without incentives and training, this activity is likely to be carried out more and more by large producers, with a high number of animals and high productivity.
\end{abstract}

Keywords: Legislation. Milk. Normative Instructions.

\section{Introdução}

O Brasil é um dos maiores produtores mundiais de leite de vaca, tendo ocupado o sexto lugar em 2019, atrás apenas da União Europeia, Estados Unidos, Índia, Rússia e China (STATISTA, 2020). A crescente produção de leite sob inspeção no país, até 2014, apresentou dois anos de queda, voltando a aumentar a partir de 2017 (CARVALHO; ROCHA; GOMES, 2018).

O rebanho de vacas ordenhadas no Brasil atingiu seu ponto máximo no ano de 2011, com 23,2 milhões de cabeças. Esse número sofreu redução nos dois anos seguintes e, em 2014, aumentou para 23 milhões. Desde então, esse diminuiu até 2017, atingindo aproximadamente 11,5 milhões de cabeças (IBGE, 2017). A última estatística disponível pelo Instituto Brasileiro de Geografia e Estatística (IBGE) em relação ao número de vacas ordenhadas é de 2018 (PPM - IBGE, 2018), e mostra que esse número aumentou, comparado ao de 2017 , totalizando 16.357 .485 cabeças, o que equivale a $7,7 \%$ do total de bovinos no país.

Considerando-se os cinco Estados com maiores rebanhos leiteiros, o primeiro desses, Minas Gerais, possui quase três vezes o número de vacas ordenhadas existentes em Goiás, que está em segundo lugar. Além disso, levando-se em consideração o número de vacas ordenhadas no Brasil, em 2017, Minas Gerais é responsável por 25,8\%.

$\mathrm{O}$ último dado de produção de leite no Brasil, publicado pelo IBGE, é do ano de 2018 e foi de 33,8 bilhões de litros, tendo apresentado um incremento de 1,6\% em relação ao ano anterior. Um total de 5.517 municípios foi responsável pelo leite produzido em 2018, sendo que Castro, no Paraná, é o líder no ranking brasileiro, sendo responsável por $0,9 \%$ da produção nacional e 6,7\% da produção do Estado do Paraná. Na segunda e na terceira posições estão Patos de Minas (MG) e Carambeí (PR), respectivamente (IBGE, 2018).

As regiões de maior produção foram Sul e Sudeste, com $34,2 \%$ e $33,9 \%$ do total de litros produzido no país (IBGE, 2018). O maior Estado produtor foi Minas Gerais, com 8,9 bilhões de litros, seguido pelo Paraná (4,4 bilhões), Rio Grande do Sul (4,2 bilhões), Goiás (3,1 bilhões) e Santa Catarina em quarto lugar com 3 bilhões de litros produzidos em 2018.

A aquisição de leite cru feita por estabelecimentos, que 
atuam sob inspeção sanitária federal, estadual ou municipal, no ano de 2018, foi de 24,43 bilhões de litros. Essa diferença entre o total de leite produzido no País (33,8 bilhões de litros - IBGE, 2018) e a quantidade de leite cru adquirida pelos laticínios sob inspeção sanitária (IBGE, 2018a) decorrente da produção que não é fiscalizada, que correspondeu, em 2018, a $27,7 \%$ do total. De acordo com o IBGE, a aquisição de leite cru no ano de 2019, feita pelos estabelecimentos que atuam sob algum tipo de inspeção sanitária, foi de 25,01 bilhões de litros (IBGE, 2019). Em relação ao primeiro trimestre de 2020, essa aquisição foi de 6,30 bilhões de litros, o que equivale a um aumento de $1,8 \%$ em relação ao mesmo período do ano anterior (IBGE, 2020).

A produtividade média de leite teve um acréscimo de 4,7\% em 2018, em relação a 2017, tendo atingido 2.069 litros/ vaca/ ano (IBGE, 2019). A produtividade média mundial é 3,5 mil litros/ vaca/ ano, havendo vacas, nos Estados Unidos, que alcançam até 10,4 mil litros/ ano. Essa discrepância pode estar relacionada ao clima, raça, genética, alimentação, tecnologias de manejo e conforto do animal, fatores que exigem maior comprometimento financeiro do produtor (SNA, 2017). A região brasileira com maior produtividade é a região Sul, com 3,44 litros/ vaca/ ano, seguida pela região Sudeste (2,40 litros/ vaca/ ano), Centro-Oeste (1,57 litros/ vaca/ ano ), Nordeste (1,31 litros/ vaca/ ano ) e Norte com produtividade média de 1,02 litros/ vaca/ ano em 2018.

De acordo com o IBGE (2019), a Região Sul é a que apresenta rendimento mais alto e criações de maior eficiência produtiva, sendo que todos os seus Estados apresentaram produtividades superiores a 3.200 litros/ vaca/ ano. Os três municípios de melhor produtividade, em 2018, foram Araras (SP), Carambeí (PR) e Castro (PR).

Com uma produção de leite tão expressiva no Brasil, a garantia da qualidade deste produto é de extrema importância. O assunto "qualidade do leite" passou a ser discutido no País há pouco mais de duas décadas, em função da preocupação do Governo com a competitividade do setor lácteo brasileiro. No meio dos anos 1990, o MAPA iniciou uma discussão nacional, envolvendo setores científicos e econômicos ligados à cadeia leiteira, a fim de buscarem alternativas para a melhoria da qualidade do leite no país (NERO et al., 2005). Essa discussão deu origem à Portaria $n^{\circ} 166$, de 05 de maio de 1998 (BRASIL, 1998), que estabeleceu um grupo de trabalho para analisar e propor um programa de medidas, visando o aumento da competitividade e a modernização do setor leiteiro no Brasil.

Esse grupo selecionado desenvolveu uma versão inicial do Programa Nacional de Melhoria da Qualidade do Leite (PNQL), que foi submetido à consulta pública através da Portaria ${ }^{\circ}$ 56, de 17 de dezembro de 1999 (BRASIL, 1999). A partir disto, o MAPA publicou a versão definitiva das novas normas de produção de leite na Instrução Normativa ${ }^{0} 51$ (IN 51), em 18 de setembro de 2002 (BRASIL, 2002a), que estabeleceu regulamentos técnicos de identidade e qualidade para os diversos tipos de leite.

Desde então, apesar dos esforços do setor lácteo para atender aos novos padrões, vários fatores têm dificultado essa adequação, como a necessidade de melhoria de estradas para o escoamento da produção e a falta de treinamento dos produtores rurais quanto às boas práticas de ordenha (BORGES et al., 2015).

Diante do não cumprimento das novas metas de Contagem Padrão em Placas (CPP) e de Contagem de Células Somáticas (CCS) pelos produtores de leite, o MAPA prorrogou mais de uma vez os prazos estabelecidos para essa adequação, através das INs 32, 62, 07 e 31 (BRASIL, 2011a; 2011b; 2016; 2018a), além de atualizar os parâmetros de qualidade deste alimento na IN 62 (BRASIL, 2011b). Como a cadeia produtiva leiteira não conseguiu, novamente, adequar-se às regras estabelecidas, em 26 de novembro de 2018, o MAPA publicou as Instruções Normativas $n^{\circ} 76$ e 77 (BRASIL, 2018b; 2018c), revogando todas as anteriores. Mais recentemente, no dia 06 de novembro de 2019, o MAPA publicou as INs 58 e 59, alterando as INs 76 e 77 (BRASIL, 2019a; 2019b).

Diante do exposto, será que essa pressão exercida pelo MAPA sobre as indústrias e os produtores tem surtido efeito? O Brasil tem produzido leite de melhor qualidade nesses últimos 20 anos, seguindo as mudanças impostas pelas legislações? O objetivo deste trabalho foi realizar uma revisão bibliográfica sobre a qualidade do leite cru produzido entre os anos de 2000 e 2020 e relacionar esses resultados às Instruções Normativas, que regulamentam os critérios de identidade e qualidade desse tipo de leite, além de discutir as tendências relativas à atividade leiteira.

\section{Material e Métodos}

A revisão bibliográfica sobre a qualidade do leite brasileiro entre os anos de 2000 e 2020 foi realizada por meio da busca de artigos no Google acadêmico. Para isso, foram utilizados os termos "qualidade leite cru Brasil CBT" e "qualidade leite cru Brasil CCS”, nas línguas portuguesa e inglesa.

Após a leitura de todos os artigos obtidos, foram eliminados aqueles em que foram analisadas amostras de leite cru adquiridas no comércio informal. De cada artigo, foram extraídos os seguintes dados: número de amostras analisadas, ano da análise, Estado no qual foram coletadas as amostras, CBT e CCS médias. Uma tabela foi elaborada contendo todos esses dados, em ordem cronológica, utilizando-se o programa Excel, para que esses fossem analisados.

A proporção de amostras coletadas entre os Estados brasileiros foi comparada pelo teste de Qui-Quadrado. As contagens médias de CCS e CBT foram comparadas ao longo dos anos e entre os Estados pelo teste de Kruskal-Wallis. Todas as análises foram feitas no programa Statistica 10.0, com significância de 5\%.

A busca pelas legislações brasileiras que regulamentam os 
critérios de identidade e qualidade do leite cru no período de 2000 a 2020 foi realizada no site do MAPA. As Instruções Normativas foram lidas e analisadas, e dessas foram selecionadas as principais exigências e/ou alterações relativas aos critérios de identidade e qualidade do leite cru, como pode ser observado no Quadro 1.

Quadro 1 - Instruções Normativas utilizadas neste trabalho de revisão, data de publicação e principais exigências/alterações relativas ao leite cru

\begin{tabular}{|c|c|c|}
\hline IN & Ano & Principais exigências/alterações em relação ao leite cru \\
\hline 51 & 2002 & $\begin{array}{l}\text { Refrigeração do leite cru na propriedade. } \\
\text { Permissão do uso de tanques comunitários por expansão direta. } \\
\text { Período máximo de transporte até a indústria é de } 48 \mathrm{~h} \text {, em caminhão isotérmico. } \\
\text { Estabelecidos requisitos físico-químicos, microbiológicos e de resíduos químicos do leite cru refrigerado. } \\
\text { Estabelecidos valores máximos de CBT e CCS, com prazos de adequação. }\end{array}$ \\
\hline 32 & 2011 & $\begin{array}{l}\text { Prorroga a vigência dos prazos estabelecidos pela IN 51, para adequação de CBT e CCS. } \\
\text { Institui um grupo de trabalho com o objetivo de estabelecer novas diretrizes do Programa Nacional de Melhoria da } \\
\text { Qualidade do Leite, e definir competências e compromissos de cada elo envolvido na cadeia produtiva leiteira. }\end{array}$ \\
\hline 62 & 2011 & $\begin{array}{l}\text { Prorroga a vigência dos prazos estabelecidos pela IN 32, para adequação de CBT e CCS. } \\
\text { Estabelece o controle sistemático de parasitas e mastites, além do controle rigoroso de brucelose e tuberculose. } \\
\text { Torna obrigatória a realização de análises para pesquisa de resíduos de inibidores e antibióticos no leite. } \\
\text { O índice crioscópico, que apresentava somente valor máximo de }-0530{ }^{\circ} \mathrm{H} \text {, passa a ter limite mínimo, de }-0,550{ }^{\circ} \mathrm{H} \text {. }\end{array}$ \\
\hline 07 & 2016 & Prorroga a vigência dos prazos estabelecidos pela IN 62, para adequação de CBT e CCS. \\
\hline 31 & 2018 & Prorroga a vigência dos prazos estabelecidos pela IN 07, para adequação de CBT e CCS. \\
\hline $\begin{array}{c}76 / \\
77\end{array}$ & 2018 & $\begin{array}{l}\text { Revoga todas as INs anteriores. } \\
\text { Ficam estabelecidos apenas limites máximos para os parâmetros de CBT e CCS, sem prazos para adequações, como } \\
\text { vinha sendo preconizado desde } 2002 \text {. } \\
\text { Não é mais permitido o uso de tanques de imersão para refrigeração do leite. } \\
\text { A temperatura do leite cru refrigerado a ser recebido no estabelecimento processador deve ser no máximo de } 7{ }^{\circ} \mathrm{C} \text {, } \\
\text { admitindo-se, excepcionalmente, o recebimento até } 9^{\circ} \mathrm{C} \text {. } \\
\text { Nas análises diárias do leite cru refrigerado, fica estabelecida a pesquisa de neutralizantes de acidez, reconstituintes } \\
\text { de densidade e de índice crioscópico, pesquisa de substâncias conservadoras e análise de, no mínimo, duas classes de } \\
\text { antimicrobianos. } \\
\text { Com frequência determinada pelo programa de autocontrole da indústria, os leites devem ser analisados para todos as } \\
\text { classes de antimicrobianos para os quais existam especificações de triagem analíticas disponíveis. } \\
\text { Os parâmetros físico-químicos do leite cru refrigerado são mantidos, com exceção do índice crioscópico, que tem seu } \\
\left.\text { valor mínimo alterado de }-0,550^{\circ} \mathrm{H} \text { para }-0,555^{\circ} \mathrm{H} \text { e da inclusão da pesquisa de lactose anidra (mínimo de } 4,3 \mathrm{~g} / 100 \mathrm{~g}\right) \text {. } \\
\text { Dentro do Programa de Autocontrole (PAC) dos estabelecimentos, deve constar como é realizada a educação continuada } \\
\text { dos produtores rurais, envolvendo treinamento nas boas práticas de ordenha. } \\
\text { O produtor rural e o transportador de leite que não atendem totalmente ou parcialmente os critérios e padrões } \\
\text { determinados pelas IN } 76 \text { e } 77 \text {, podem ser desvinculados pelo estabelecimento industrial. No caso dos produtores, é } \\
\text { considerada a média geométrica de três meses. }\end{array}$ \\
\hline $\begin{array}{c}58 / \\
59\end{array}$ & 2019 & $\begin{array}{l}\text { Altera as INs } 76 \text { e } 77 \text {. } \\
\text { No caso de não haver resultados suficientes para computar a média geométrica trimestral do leite produzido } \\
\text { individualmente por cada rebanho, o resultado de cada mês subsequente substitui a média geométrica, até que ocorra o } \\
\text { restabelecimento da média geométrica trimestral calculada. } \\
\text { Para iniciar a coleta de leite de novos rebanhos, o estabelecimento deve assegurar que estes atendem às boas práticas } \\
\text { agropecuárias e que o leite esteja dentro do padrão para CBT, mediante confirmação de laudo emitido por laboratório } \\
\text { da RBQL. } \\
\text { Nos casos de restabelecimento da coleta de produtores que apresentaram três médias geométricas consecutivas acima de } \\
300 \text { mil células por mL, deve ser apresentado apenas um resultado de CBT dentro do padrão. } \\
\text { O laticínio deve realizar a CBT do leite cru refrigerado antes de seu processamento, com frequência mínima mensal, em } \\
\text { um laboratório da RBQL, devendo atender ao padrão disposto no Regulamento Técnico específico. } \\
\text { O estabelecimento não é mais obrigado a descrever a educação continuada aos produtores no PAC. }\end{array}$ \\
\hline
\end{tabular}
Fonte: Brasil (2002, 2011a, 2011b, 2016, 2018a).

Os dados de CBT e CCS médios observados nos artigos científicos foram relacionados às legislações vigentes no momento em que as amostras foram analisadas, através da elaboração de tabelas e discussão dos resultados.

\section{Resultados e Discussão}

\subsection{Qualidade do leite cru no Brasil nos últimos 15 anos}

Foram recuperados 59 artigos publicados entre 2005 e
2020, os quais analisaram 249.990 amostras de leite entre 2002 e 2018. Nesse período, a distribuição da amostragem não foi uniforme entre os Estados brasileiros $\left(X^{2}=922944,30\right.$; $\mathrm{P}<0,01$ ), com mais amostras coletadas de Minas Gerais, Goiás e Paraná, os quais juntos representaram $78 \%$ do total encontrado (Figura 1). Também é possível perceber que entre os artigos selecionados não houve amostragem proveniente da região Norte e dos Estados de Mato Grosso, Rio de Janeiro e Espírito Santo. 
Figura 1 - Distribuição geográfica do número de amostras analisadas entre 2002 e 2018, recuperadas de 59 artigos publicados entre 2005 e 2020

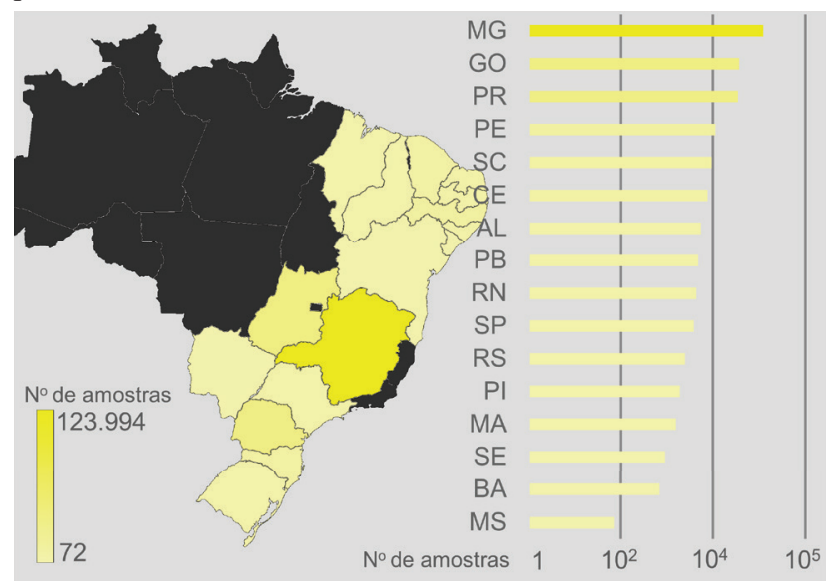

Fonte: Dados da pesquisa

A CBT também não foi uniforme entre os Estados brasileiros ( $\mathrm{P}=0,01$ Kruskal-Wallis), com maiores contagens médias nos Estados de Pernambuco, Maranhão e Sergipe. Nesses três Estados, a contagem média de CBT foi de 6,47 log cel $\mathrm{mL}^{-1}$ (Figura 2). Por sua vez, as contagens médias de CCS foram mais uniformes entre os Estados nos quais os estudos foram feitos ( $\mathrm{P}=0,47$ Kruskall-Wallis), com resultados entre 5,01 e 5,92 log cel $\mathrm{mL}^{-1}$ (Figura 2).

Figura 2- Contagem bacteriana total (a) e contagem de células somáticas (b) em amostras de leite analisadas entre 2002 e 2018, recuperadas de 59 artigos publicados entre 2005 e 2020

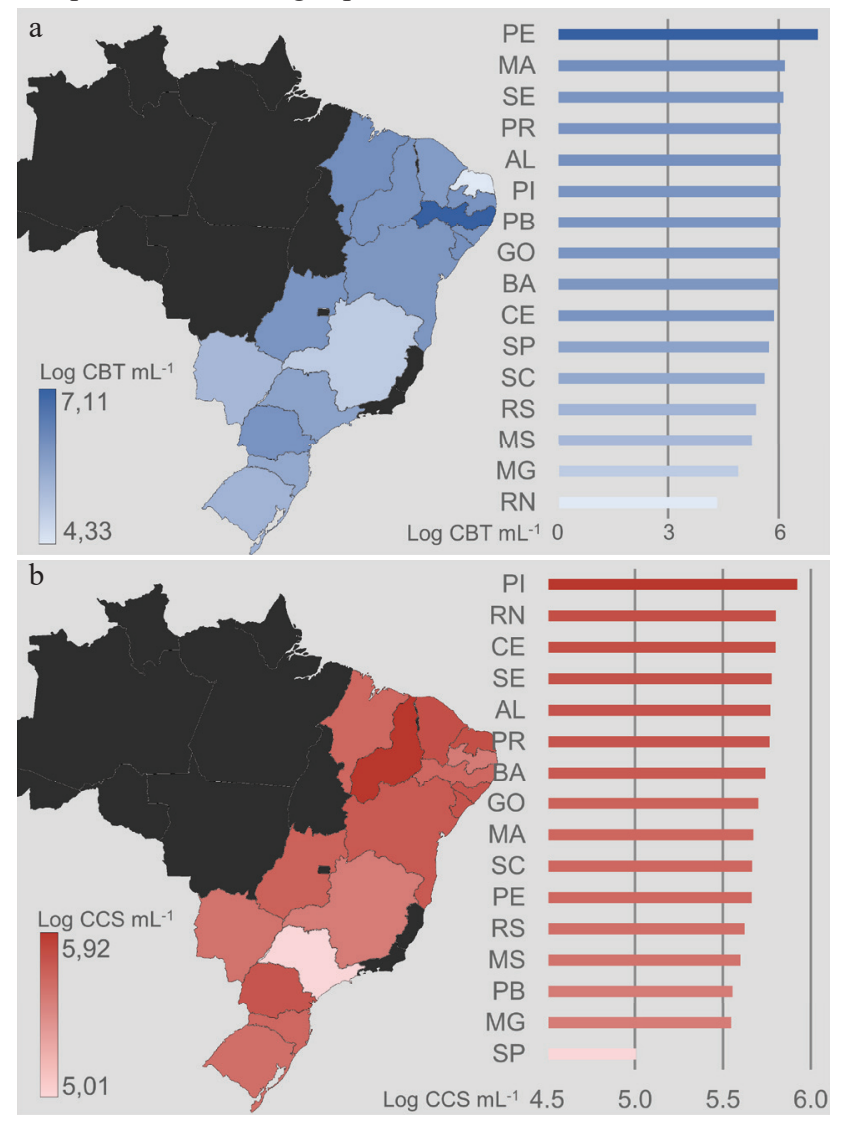

Fonte: Dados da pesquisa
Nas publicações entre 2002 e 2018, a contagem média das amostras de leite foi de 3,39 milhões cel $\mathrm{mL}^{-1}$ para CBT e 536 mil cel $\mathrm{mL}^{-1}$ para CCS (Figura 3). Não foi possível observar variação significativa $(\mathrm{p}>0,05)$ nas contagens médias de CCS e CBT ao longo dos anos.

Figura 3 - Medianas, quartis (25\%-75\%) e valores mínimos e máximos da contagem bacteriana total $\left(\log \mathrm{CBT} \mathrm{mL}^{-1}\right)$ e células somáticas (log CCS $\left.\mathrm{mL}^{-1}\right)$ de leite cru proveniente de artigos publicados entre 2005 e 2020 e com coleta de amostras entre 2002 e 2018

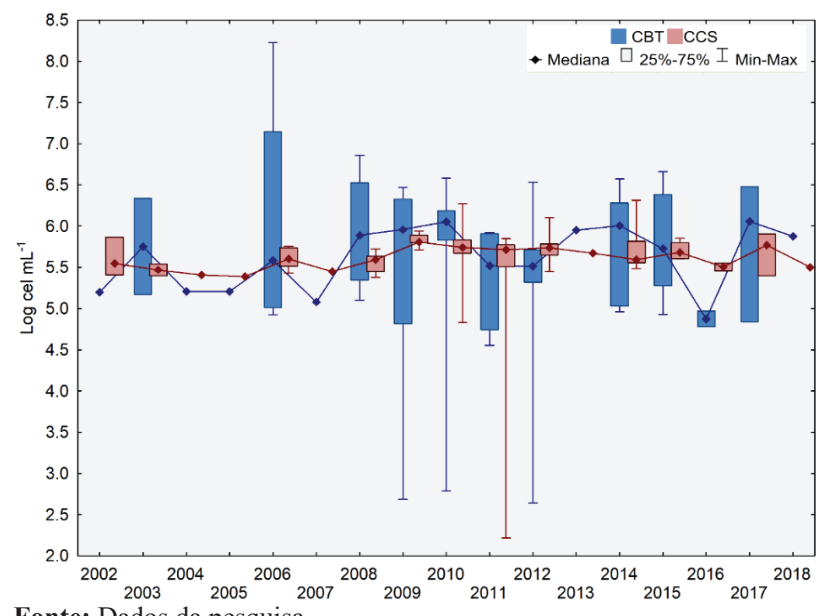

Fonte: Dados da pesquisa

\subsection{Relação entre a qualidade do leite cru e as legislações vigentes no Brasil}

A adoção de limites para CCS e CBT no leite cru, desde 2002, foi um avanço inquestionável, e sua intenção é a melhora da qualidade deste produto no Brasil, em um momento em que o consumidor passou a ser mais exigente em relação aos alimentos (BRASIL, 2002, PINHEIRO et al., 2011).

Serão relacionadas às legislações vigentes em cada período de tempo com os parâmetros médios de qualidade do leite cru observados nos 59 artigos recuperados no Google Acadêmico. Os dados estão separados por regiões brasileiras, em função das diferenças das datas máximas para adequação para Norte e Nordeste, em relação ao Sul, Sudeste e CentroOeste. As INs 76 e 77 não estão citadas nas tabelas, uma vez que passaram a vigorar em 2019 e não foi encontrado artigo em que se analisaram amostras a partir desta data.

No início da primeira fase de vigência da IN 51, os valores médios de CBT observados nas amostras de leite avaliadas no período, nas regiões Sul, Sudeste e Centro-Oeste do Brasil, ainda se encontravam acima do valor máximo estabelecido. Porém, a partir da segunda fase, em 2008, essa média passou a atender a legislação, mantendo esse comportamento até o final de 2011 (Quadro 2). 
Quadro 2 - Relação entre as legislações brasileiras de leite vigentes em cada período de tempo e os valores médios de CCS e CBT de amostras de leite cru avaliadas entre 2002 e 2018, nas regiões Sul, Sudeste e Centro-Oeste

\begin{tabular}{|c|c|c|c|}
\hline IN & $\begin{array}{c}\text { Data de } \\
\text { vigência }\end{array}$ & $\begin{array}{c}\text { Valores } \\
\text { máximos* } \\
\text { CBT (UFC/mL) } \\
\text { CCS (células/ } \\
\text { mL) }\end{array}$ & $\begin{array}{c}\text { Valores médios } \\
\text { observados na } \\
\text { literatura CBT } \\
\text { (UFC/mL) } \\
\text { CCS (células/mL) }\end{array}$ \\
\hline $\mathbf{5 1}$ & $\begin{array}{c}07 / 2005 \mathrm{a} \\
07 / 2008\end{array}$ & $\begin{array}{c}\mathrm{CBT}=1,0 \times 10^{6} \\
\mathrm{CCS}=1,0 \times 10^{6}\end{array}$ & $\begin{array}{c}\mathrm{CBT}=1,2 \times 10^{6} \\
\mathrm{CCS}=3,8 \times 10^{5}\end{array}$ \\
\hline $\mathbf{5 1}$ & $07 / 2008 \mathrm{a}$ & $\mathrm{CBT}=7,5 \times 10^{5}$ & $\mathrm{CBT}=5,8 \times 10^{5}$ \\
$07 / 2011$ & $\mathrm{CCS}=7,5 \times 10^{5}$ & $\mathrm{CCS}=5,7 \times 10^{5}$ \\
\hline $\mathbf{5 1 , 3 2}$ & $07 / 2011 \mathrm{a}$ & $\mathrm{CBT}=7,5 \times 10^{5}$ & $\mathrm{CBT}=3,6 \times 10^{5}$ \\
\hline $\mathbf{6 2}$ & $01 / 2011$ & $\mathrm{CCS}=7,5 \times 10^{5}$ & $\mathrm{CCS}=3,4 \times 10^{5}$ \\
\hline $\mathbf{6 2} \mathbf{7}$, & $07 / 2014$ & $\mathrm{CBT}=6,0 \times 10^{5}$ & $\mathrm{CBT}=1,1 \times 10^{6}$ \\
$\mathbf{3 1}$ & $05 / 2014 \mathrm{a}$ & $\mathrm{CBT}=3,0 \times 10^{5}$ & $\mathrm{CCS}=6,3 \times 10^{5}$ \\
\hline
\end{tabular}

"mínimo de uma análise mensal com média geométrica sobre 3 meses.

Fonte: Brasil (2002, 2011a, 2011b, 2016, 2018a).

A partir do início de 2012, com o início da vigência da IN 62 e a redução do valor máximo de CBT permitido, a média da contagem de bactérias nas amostras analisadas passou a não mais atender à legislação, apresentando valores acima dos permitidos. Resultados semelhantes foram observados em relação à CCS, que atendeu aos padrões da legislação de 2005 a 2011, deixando de atender quando o nível de exigência foi aumentado (Quadro 2).

$\mathrm{Na}$ região Nordeste do Brasil se verifica que houve um atraso para a adequação dos valores de CBT, quando comparada às regiões Sul, Sudeste e Centro-Oeste. Em relação aos valores médios de CCS, esses antederam às exigências das legislações desde o início da vigência da IN 51 (Quadro 3).

Quadro 3 - Relação entre as legislações brasileiras de leite vigentes em cada período de tempo e os valores médios de CCS e CBT de amostras de leite cru avaliadas entre 2002 e 2018, na região Nordeste.

\begin{tabular}{|c|c|c|c|}
\hline IN & $\begin{array}{c}\text { Data de } \\
\text { vigência }\end{array}$ & $\begin{array}{c}\text { Valores máximos* } \\
\text { CBT (UFC/mL) } \\
\text { CCS (células/mL) }\end{array}$ & $\begin{array}{c}\text { Valores médios } \\
\text { observados na } \\
\text { literatura CBT } \\
\text { (UFC/mL) CCS } \\
\text { (células/mL) }\end{array}$ \\
\hline $\mathbf{5 1}$ & $\begin{array}{c}07 / 2007 \text { a } \\
07 / 2010\end{array}$ & $\begin{array}{c}\mathrm{CBT}=1,0 \times 10^{6} \\
\mathrm{CCS}=1,0 \times 10^{6}\end{array}$ & $\begin{array}{c}\mathrm{CBT}=1,2 \times 10^{6} \\
\mathrm{CCS}=5,6 \times 10^{5}\end{array}$ \\
\hline $\mathbf{5 1}$ & $\begin{array}{c}07 / 2010 \mathrm{a} \\
07 / 2012\end{array}$ & $\mathrm{CBT}=7,5 \times 10^{5}$ & $\mathrm{CBT}=9,5 \times 10^{5}$ \\
$\mathrm{CCS}=7,5 \times 10^{5}$ & $\mathrm{CCS}=5,9 \times 10^{5}$ \\
\hline $\mathbf{3 2}$ & $\begin{array}{c}07 / 2012 \mathrm{a} \\
12 / 2012\end{array}$ & $\begin{array}{c}\mathrm{CBT}=7,5 \times 10^{5} \\
\mathrm{CCS}=7,5 \times 10^{5}\end{array}$ & $\begin{array}{c}\mathrm{CBT}=1,6 \times 10^{5} \\
\mathrm{CCS}=6,1 \times 10^{5}\end{array}$ \\
\hline $\mathbf{6 2}$ & $\begin{array}{c}01 / 2013 \mathrm{a} \\
06 / 2015\end{array}$ & $\begin{array}{c}\mathrm{CBT}=6,0 \times 10^{5} \\
\mathrm{CCS}=6,0 \times 10^{5}\end{array}$ & $\begin{array}{c}\mathrm{CBT}=\mathrm{NE} \\
\mathrm{CCS}=\mathrm{NE}\end{array}$ \\
\hline $\mathbf{6 2 , 7}$, & $07 / 2015 \mathrm{a}$ & $\mathrm{CBT}=3,0 \times 10^{5}$ & $\mathrm{CBT}=3,0 \times 10^{6 * *}$ \\
$\mathbf{3 1}$ & $06 / 2019$ & $\mathrm{CCS}=5,0 \times 10^{5}$ & $\mathrm{CCS}=8,0 \times 10^{5 *}$ \\
\hline
\end{tabular}

*mínimo de uma análise mensal com média geométrica sobre 3 meses.

**dado de um único artigo científico. $\mathrm{NE}=$ não encontrado trabalho em que foram realizadas análises nesse período.

Fonte: Brasil (2002, 2011a, 2011b, 2016, 2018a).

Infelizmente, não é possível avaliar o comportamento da
CBT e da CCS na região Nordeste a partir de 2013, com base na literatura pesquisada, uma vez que não foram encontrados artigos científicos em que se analisaram amostras entre 2013 e 2015. Além disso, somente um artigo relativo ao período de 2015 a 2019 foi recuperado, cujas análises foram realizadas em 2017.

Vale lembrar que analisar a qualidade do leite com informações obtidas de artigos científicos publicados possui suas particularidades. Alguns estudos, por exemplo, não informaram se as propriedades amostradas estavam ou não cadastradas em laticínios sob inspeção. Essa realidade pode afetar os resultados de qualidade, se comparada aos estudos com amostragem estrita de produtores cadastrados em estabelecimentos inspecionados. Isso, porque produtores vinculados aos estabelecimentos formais devem ser monitorados, periodicamente, quanto à qualidade do leite, além de que usualmente são incentivados pelo pagamento por qualidade. Consequentemente, estudos com universo amostral restrito aos laticínios inspecionados tendem a ter melhores resultados microbiológicos.

Outra limitação é que alguns estudos coletaram amostras diretamente dos animais, não representando o leite de todo o rebanho de uma propriedade. Isso pode minimizar os valores de CCS, caso a amostragem seja proveniente de animais sadios, ou pode maximizá-los, caso a amostragem seja, predominantemente, constituída por animais com mastite. Há também as limitações temporal e geográfica, uma vez que o acompanhamento das publicações ao longo dos anos não é exclusivo de uma única região, sendo mais vulnerável às oscilações de resultados.

Portanto, o fato de que não houve variação significativa ( $p>0,05)$ nas contagens médias de CCS e CBT ao longo dos anos deve ser interpretada com parcimônia. Esse resultado não exclui a possibilidade de melhoria da qualidade microbiológica do leite brasileiro ao longo dos anos. O que se pode afirmar é que a melhoria de qualidade não é nítida, quando são analisados os dados proveniente de publicações científicas.

\subsection{Perspectivas futuras}

Com o intuito de melhorar o atendimento à legislação, desde a publicação da IN 62 (BRASIL, 2011b) o MAPA exige que as empresas tenham um programa de educação continuada dos participantes, cuja eficácia deve ser demonstrada pelos resultados de análises de qualidade do leite dos rebanhos dos seus fornecedores, realizadas pela Rede Brasileira de Laboratórios da Qualidade do Leite.

No entanto, o que acontecerá com o pequeno produtor que não conseguir se enquadrar nas normas? Será desvinculado do estabelecimento industrial, saindo do mercado e, finalmente, abandonando a atividade? Como observado em outros países (New Zealand's Environmental Reporting Series, 2016; OCLA, 2019; STATISTICS CANADA, 2012; USDA, 2012; 
USDA, 2017) somente as propriedades que produzem leite de boa qualidade serão mantidas?

Atualmente, essa tendência já tem sido observada no país. O último Censo Agropecuário (IBGE, 2019b) mostra que o número de propriedades que produziram leite de vaca, no Brasil, em 2017, foi 13\% menor que o observado no Censo de 2006 , sendo que a maioria dos estabelecimentos que deixou de existir são pequenos, com menos de 5 hectares. Essa redução já tem sido observada há algum tempo em países, como: Estados Unidos, Canadá, Argentina e Nova Zelândia (New Zealand's Environmental Reporting Series, 2016; OCLA, 2019; STATISTICS CANADA, 2012; USDA, 2012; USDA, 2017).

De acordo com os últimos dois Censos Agropecuários americanos (USDA, 2012; USDA, 2017), o número de fazendas produtoras de leite no País apresentou um decréscimo de $15 \%$. De acordo com as pesquisas, os estabelecimentos que tinham entre 10 e 99 vacas foram os que mais diminuíram no período, enquanto os que continham mais de 2.500 animais apresentaram um aumento de $24 \%$. No Canadá, o Censo tem mostrado que o número de propriedades leiteiras tem diminuído $10 \%$ a cada pesquisa, enquanto a consolidação das fazendas que continuam no ramo tem aumentado (STATISTICS CANADA, 2012).

Na Nova Zelândia, o número de fazendas leiteiras diminuiu $23,5 \%$ entre 2002 e 2016, com um total de 19.659 e 15.039 fazendas, respectivamente. Apesar disso, a área total das fazendas envolvidas na atividade leiteira aumentou $22,6 \%$, indicando que algumas fazendas estão se tornando maiores e mais especializadas (New Zealand's Environmental Reporting Series, 2016).

Outra característica verificada nos Estados Unidos está relacionada ao número de animais nas fazendas. As fazendas maiores, no período entre os dois Censos (USDA, 2012; USDA, 2017), apresentaram um aumento no número de vacas (27\%), enquanto as menores perderam $19 \%$ de seus animais. Com isso, verifica-se que a maioria dos animais (66\%) ordenhados no País, em 2017, era de propriedade de apenas $4 \%$ das fazendas. Esse fato também foi verificado no Canadá (STATISTICS CANADA, 2012).

Comportamento semelhante vem sendo observado na Argentina. De acordo com o Observatório da Cadeia Láctea (OCLA, 2019), 51,9\% das fazendas leiteiras do País, que produzem menos de 2 mil litros por dia, contribuem apenas com $18,2 \%$ do leite total. Todavia, as fazendas que produzem mais de 10 mil litros por dia, que representam apenas 3,3\%, contribuem com 19,6\% do leite total. Esses estudos concluem que 357 fazendas grandes produzem, por dia, a mesma quantidade de leite que 5.734 fazendas pequenas.

Esse fato também é tendência no Brasil e, em um futuro próximo, o leite brasileiro provavelmente virá de um número menor de fazendas, que serão cada vez maiores e mais automatizadas, o que refletirá em uma melhor qualidade. Além disso, parece ser tendência um número cada vez menor de jovens trabalhando nas propriedades.

Em relação ao futuro da produção brasileira de leite, Vilela (2015) estima que está será de 47,5 milhões de toneladas em 2025, volume um pouco acima do previsto pela Federação das Indústrias do Estado de São Paulo, que é de 44,4 milhões de toneladas em 2026 (FIESP, 2016). De acordo com o OECDFAO Agricultural Outlook 20182027, a previsão é um pouco menos otimista: produção de 35,9 milhões de toneladas de leite em 2027 (OECD/FAO, 2018).

Segundo a OECD/FAO (2018), em 2028, a depreciação da moeda na Argentina, Brasil e México (em relação ao dólar americano) irá impulsionar o crescimento nas exportações de leite desses países, uma vez que esses se tornarão mais competitivos em relação aos Estados Unidos.

Britt e colaboradores (2017) citam suas visões para as fazendas e vacas leiteiras no ano de 2067 , como descrito a seguir: em função do aumento da temperatura nas zonas tropicais e temperadas, a produção de leite não ocorrerá mais em regiões áridas; o consumo de leite irá aumentar, uma vez que esse alimento proporciona mais eficientemente os nutrientes essenciais, quando comparado a outros sistemas do agronegócio; as fazendas de leite serão modernizadas nos países em desenvolvimento e a produtividade irá aumentar; melhorias genéticas incluirão, além do genoma, o epigenoma e o microbioma; o tamanho das fazendas irá aumentar e sensores integrados, robôs e automações irão substituir grande parte do trabalho manual; os rebanhos serão vistos como super organismos e estudos trarão melhoria na produtividade, saúde e bem-estar dos animais.

\section{Conclusão}

Uma vez que o Brasil é um dos maiores produtores de leite no mundo, é de extrema importância que a qualidade deste alimento esteja bem regulamentada no país. Desde o início de vigência das Instruções Normativas, que regulamentam os critérios de identidade e qualidade do leite no país, verificase uma certa dificuldade dos produtores no cumprimento das exigências, principalmente, quando essas se tornaram mais rigorosas, com o avançar do tempo.

Além das legislações, talvez, sejam necessários mais incentivos e treinamento, principalmente ao pequeno produtor, para que ele possa ser competitivo e continuar na atividade. Sem isso, provavelmente, muitos pequenos produtores acabarão abandonando a atividade, que passará a ser exercida, cada vez mais, em propriedades maiores, com grande número de animais e grande produtividade.

\section{Referências}

BRASIL. Portaria $n^{\circ} 166$, de 05 de maio de 1998. Cria grupo de trabalho para analisar e propor programa e medidas visando ao aumento da competitividade. Diário Oficial da União, Brasília, p.42, 06 mai. 1998. Seção 1.

BRASIL. Portaria $n^{\circ}$ 56, de 17 de dezembro de 1999. Submete a consulta pública os regulamentos técnicos de padrão de identidade e qualidade de leite. Diário Oficial da União, Brasília, p.34, 08 
dez. 1999. Seção 2.

BRASIL. Instrução Normativa n.51 de 18 de setembro de 2002. Regulamento Técnico de Produção, Identidade e Qualidade de Leite Tipo A, Tipo B, Tipo C e Cru refrigerado. Diário Oficial da União, Brasília, 29 set. 2002. Seção 1, p.13.

BRASIL. Instrução Normativa no 32, de 30 de junho de 2011. Prorroga vigência da Instrução Normativa MAPA no 51, de 18 de setembro de 2002. Diário Oficial da União, Brasília. 01 jul. de 2011a.

BRASIL. Instrução Normativa 62, de 29 de dezembro de 2011. Aprova o Regulamento Técnico de Produção, Identidade e Qualidade do Leite tipo A, o Regulamento Técnico de Identidade e Qualidade de Leite Cru Refrigerado, o Regulamento Técnico de Identidade e Qualidade de Leite Pasteurizado e o Regulamento Técnico da Coleta de Leite Cru Refrigerado e seu Transporte a Granel. Diário Oficial da União, 30 de Dezembro de 2011b, Seção 1, p.6

BRASIL. Instrução Normativa 7 de 03 de maio de 2016. Diário Oficial da União, Seção 1, 04 de maio de 2016, seção 1, p.11.

BRASIL. Instrução Normativa 31 de junho de 2018. Diário Oficial da União, Seção 1, 02 de julho de 2018a, seção 1, p.2.

BRASIL. Instrução Normativa 76 de novembro de 2018. Aprova os Regulamentos Técnicos que fixam a identidade e as características de qualidade que devem apresentar o leite cru refrigerado, o leite pasteurizado e o leite pasteurizado tipo A. Diário Oficial da União, Seção 1, 30 de novembro de 2018b, Seção 1, p.9.

BRASIL. Instrução Normativa 77 de novembro de 2018. Estabelece os critérios e procedimentos para a produção, acondicionamento, conservação, transporte, seleção e recepção do leite cru em estabelecimentos registrados no serviço de inspeção oficial. Diário Oficial da União, Seção 1, 30 de novembro de 2018c, Seção 1, p.10.

BRASIL. Instrução Normativa no 58, de 06 de novembro de 2019. Altera a Instrução Normativa MAPA no 76, de 26 de novembro de 2018. Diário Oficial da União, Brasília. 07 nov. de 2019a.

BRASIL. Instrução Normativa no 59, de 06 de novembro de 2019. Altera a Instrução Normativa MAPA no 77, de 26 de novembro de 2018. Diário Oficial da União, Brasília. 07 nov. de 2019b.

BRITT, J.H. et al. Invited review: learning from the future - a vision for dairy farms and cows in 2067. J. Dairy Sci., v.101, p. 3722-3741, 2018. doi: 10.3168/jds.2017-14025.

CARVALHO, G.R.; ROCHA, D.T.; GOMES, I.R. O mercado de leite em 2017. Embrapa, 2018. Disponível em: https://ainfo. cnptia.embrapa.br/digital/bitstream/item/184516/1/CT-118-OMercado-do-Leite-em-2017.pdf. Acesso em: nov/ 2019.

FIESP. Outlook Fiesp 2026: projeções para o agronegócio brasileiro / Federação das Indústrias do Estado de São Paulo. São Paulo: FIESP, 2016.

IBGE. Censo agropecuário 2017. IBGE, 2017. Disponível em: https://www.ibge.gov.br/estatisticas/economicas/ agricultura-e-pecuaria/21814-2017-censo-agropecuario. htmL?=\&t=resultados. Acesso em: out. 2019.

IBGE. Pesquisa da Pecuária Municipal. IBGE, 2018. Disponível em: https://biblioteca.ibge.gov.br/visualizacao/periodicos/84/ ppm_2018_v46_br_informativo.pdf. Acesso em: out. 2019.

IBGE. Pesquisa Trimestral do Leite. IBGE, 2018a. Disponível em: https://biblioteca.ibge.gov.br/visualizacao/periodicos/2380/ epp_2019_4tri.pdf. Acesso em: out. 2019.

IBGE. Pesquisa Trimestral do Leite. IBGE, 2019. Disponível em: https://biblioteca.ibge.gov.br/visualizacao/periodicos/2380/ epp_2019_2tri.pdf. Acesso em: out. 2019.

IBGE. Pesquisa Trimestral do Leite. IBGE, 2020. Disponível em: https://biblioteca.ibge.gov.br/visualizacao/periodicos/2380/ epp_2020_1tri.pdf. Acesso em: out. 2019.

NERO, L.A. et al. Leite cru de quatro regiões leiteiras brasileiras: perspectivas de atendimento dos requisitos microbiológicos estabelecidos pela Instrução Normativa 51. Ciên. Tecnol. Alim., v.25, n.1, 2005. doi: 10.1590/S0101-20612005000100031.

New Zealand's Environmental Reporting Series. Change in farm numbers and farm size. Environmental indicators. 2016. Disponível em: http:/archive.stats.govt.nz/browse_for_stats/ environment/environmental-reporting-series/environmentalindicators/Home/Land/farm-size-and-numbers.aspx. Acesso em: dez. 2019.

OCLA. Observatorio de la Cadena Lactea Argentina. Estructura de la Producción Primaria. OCLA, 2019. Disponível em: http:// www.ocla.org.ar/contents/news/details/14685673-estructura-dela-produccion-primaria. Acesso em: dez. 2019.

OECD/FAO. "OECD-FAO Agricultural Outlook", OECD Agriculture statistics (database), 2018. Disponível em: http://www. fao.org/publications/oecd-fao-agricultural-outlook/2018-2027/ en/. Acesso em: out/ 2019.

PINHEIRO, F.A. et al. Perfil dos consumidores em relação à qualidade de alimentos e hábitos de compras. UNOPAR Cient. Ciênc. Biol. Saúde, v.13, n.2, p.95-102, 2011. doi: https://doi. org/10.17921/2447-8938.2011v13n2p\%25p.

SNA. Sociedade Nacional de Agricultura. Produtividade da Pecuária leiteira é inferior à metade da média mundial. SNA, 2017. Disponível em: https://www.sna.agr.br/produtividade-dapecuaria-leiteira-e-inferior-a-metade-da-media-mundial/. Acesso em: out. 2019.

STATISTA. Major producers of cow milk worldwide in 2019, by country (in million metric tons). STATISTA, 2020. Disponível em: https://www.statista.com/graphic/1/268191/cow-milkproduction-worldwide-top-producers.jpg. Acesso em: ago. 2020.

Statistics Canada. Census of Agriculture. The Daily, 2012. Disponível em: http://www.statcan.gc.ca/daily-quotidien/120510/ dq120510a-eng.htm. Acesso em out. 2019.

USDA. Census of Agriculture. USDA, 2012. Disponível em: https://www.nass.usda.gov/Publications/AgCensus/2012/. Acesso em: out. 2019.

USDA. Census of Agriculture. USDA, 2017. Disponível em: https://www.nass.usda.gov/Publications/AgCensus/2017/. Acesso em: out/ 2019.

VILELA, D. Para onde caminha o leite. Rev. Balde Branco, n. 603, p. 41-43, 2015. 